\title{
A low molecular weight factor from sea urchin eggs elevates sperm cyclic nucleotide concentrations and respiration rates
}

\author{
G. S. Kopf and D. L. Garbers \\ Howard Hughes Medical Institute Laboratories, Vanderbilt University School of Medicine, \\ Departments of Pharmacology and Physiology, Nashville, Tennessee 37232, U.S.A.
}

\begin{abstract}
Summary. A factor associated with sea urchin eggs that increases sperm cyclic nucleotide concentrations and respiration rates was identified as having a low molecular weight. The factor was more potent at elevating cyclic GMP concentrations than cyclic AMP concentrations, and represents the first demonstration of a factor associated with eggs that is capable of causing elevations of sperm cyclic GMP. Concentration-response curves of the crude mixture of egg factors to increase sperm cyclic AMP and cyclic GMP concentrations and respiratory rates were very similar, and comparable losses of these three activities were observed after extensive dialysis and heat treatment of the crude egg factors. The factor was partly purified by ethanol precipitation of a large molecular weight egg jelly component, and by charcoal adsorption and LH-20 chromatography of the resultant ethanol-soluble material. The factor was not extracted into a variety of organic solvents and had an apparent molecular weight of between 1000 and 2000 , as estimated by gel filtration.
\end{abstract}

\section{Introduction}

It has been known for over 50 years that soluble components associated with the ova of certain species of sea urchins have dramatic metabolic and functional effects on sea urchin spermatozoa. Some effects of these components on spermatozoa include induction of isoagglutination (Lillie, 1913), changes in motility (Lillie, 1913; Hathaway, 1963), alterations in respiration rates (Gray, 1928; Rothschild, 1952; Hathaway, 1960, 1963), development of the acrosome reaction (Dan, 1952), and promotion of fertilization (Lybing \& Hagström, 1957). Whether these effects are mediated by the same or by different components associated with the egg is not known.

Garbers \& Hardman $(1975,1976)$ reported that factors (FRE) released from the eggs of the sea urchins Strongylocentrotus purpuratus and Lytechinus pictus increased cyclic AMP concentrations in the spermatozoa of these sea urchins. A high molecular weight and low molecular weight factor, both capable of elevating sperm cyclic AMP concentrations, appeared to exist in the crude mixture of these egg factors. The high molecular weight egg factor demonstrated strict species specificity with respect to the induction of cyclic AMP elevations in spermatozoa (Tubb, Kopf \& Garbers, 1979), but the low molecular weight factor was able to elevate cyclic AMP concentrations in a variety of sea urchin species. We have been investigating the effects of these egg factors on one sperm functional change, the stimulation of oxygen consumption. Since sperm cyclic AMP changes are known to be associated with altered sperm functions such as motility and metabolic rates (Garbers, Lust, First \& Lardy, 1971b; Garbers, First \& Lardy, 1973a; Garbers, First, Gorman \& Lardy, 1973b; Hoskins, 1973; Frenkel, Peterson \& Freund, 1973; Tash \& Mann, 1973; Morton, Harrigan-Lum, Albagli \& Jooss, 1974; Rosado, Hicks, Reyes \& Blanco, 1974; Hoskins, Hall \& Munsterman, 1975; Cascieri, Amann \& Hammerstedt, 1976), 
some or all of the previously studied effects of sea-urchin egg factors on sea-urchin sperm respiration could be explained by egg factor-induced alterations of sperm cyclic AMP concentrations, and we have examined this possibility.

The present report describes the partial purification and characterization of a low molecular weight egg-associated factor from sea urchins, and its effects on sea urchin sperm respiratory rates and cyclic nucleotide metabolism.

\section{Materials and Methods}

Lytechinus pictus and Strongylocentrotus purpuratus sea urchins were purchased from PacificBiomarine, Venice, California. Tritiated cyclic nucleotides were obtained from the Radiochemical Centre (Amersham, U.K.) and New England Nuclear (Boston, Massachusetts). Dowex-50 (AG 50W X8, 100-200 mesh), Bio Gel A $1.5 \mathrm{~m}$ and Bio Gel P-6 were from Bio-Rad (Richmond, California). Sephadex G-10 and G-50 (medium), ovalbumin, chymotrypsinogen and ribonuclease were from Pharmacia (Sweden). Cytochrome c was obtained from Nutritional Biochemical Corp. (Cleveland, Ohio), theophylline was from Merck and Co. (Rahway, New Jersey), and Tris (Trizma Base), pronase and trypsin were from Sigma (St Louis, Missouri). Activated coconut charcoal (50-200 mesh) was purchased from Fisher (U.S.A.).

A table-top oxygraph (Model K-IC, Gilson Medical Electronics, Inc., Wisconsin) equipped with a Clark-type oxygen electrode and a $1.8 \mathrm{ml}$ capacity incubation chamber was used for the measurement of sperm oxygen consumption.

The heterologous system ( $S$. purpuratus egg factors and L. pictus spermatozoa) employed in these studies was selected to avoid the sperm agglutination known to occur when using the egg jelly component of the same species (Lillie, 1913). Such isoagglutination can complicate interpretation of sperm respiratory measurements. All gamete preparations and incubations were carried out in sea water at $\mathrm{pH} 8.0$.

Preparation of gametes and egg factors. Spermatozoa and eggs were collected and washed, and egg factors were prepared as previously described (Garbers \& Hardman, 1976). Experiments were initiated within 15 min after resuspension of the spermatozoa.

Determination of cyclic nucleotide concentrations. Spermatozoa were resuspended in sea water to concentrations ranging from 39 to $97.5 \mathrm{mg}$ (wet weight) cells $/ \mathrm{ml}$. The cells $(0.2 \mathrm{ml})$ were then preincubated at $15-17^{\circ} \mathrm{C}$ in sea water alone, or in sea water containing theophylline, for $5 \mathrm{~min}$. Incubations $(1 \mathrm{~min}$ ) were initiated by the addition of various quantities of sea water or egg factors. The final incubation volume was $0.65 \mathrm{ml}$. Incubations were terminated by the addition of $0.5 \mathrm{~N}$-perchloric acid, containing tracer amounts of cyclic $\left[{ }^{3} \mathrm{H}\right] \mathrm{AMP}$ or cyclic $\left[{ }^{3} \mathrm{H}\right]$ GMP for estimation of sperm cyclic nucleotide recoveries. Concentrations of cyclic nucleotides at zero time were estimated by adding the spermatozoa directly to sea water containing 0.5 $\mathrm{N}$-perchloric acid. The acidified cell suspensions were then frozen and thawed 5 times before purification of the cyclic nucleotides on Dowex-50 columns $(0.7 \times 25.0 \mathrm{~cm})$ as described by Schultz, Böhme \& Hardman (1974). The column fractions containing cyclic AMP and cyclic GMP were freeze-dried and then resuspended in 0.5-1.0 ml distilled water. Cyclic AMP was assayed by the method of Gilman (1970) as modified by Brostrom \& Kon (1974). Cyclic GMP was determined by radioimmunoassay (Steiner, Kipnis, Utiger \& Parker, 1969), as modified by Harper \& Brooker (1975).

Determination of respiration. Spermatozoa were collected as described above and stored as a suspension $(68 \cdot 5-115 \mathrm{mg}$ (wet weight) cells $/ \mathrm{ml})$ in a water bath $\left(17^{\circ} \mathrm{C}\right)$ or ice bath $\left(0^{\circ} \mathrm{C}\right)$. Various quantitites of the sperm suspension were preincubated in sea water alone or in sea water containing theophylline in a temperature-controlled $\left(17^{\circ} \mathrm{C}\right)$ chamber fitted with an oxygen electrode. The final preincubation volume was $1.8 \mathrm{ml}$. Within $2-3 \mathrm{~min}$ after addition of the spermatozoa, the respiratory rates had reached a constant basal rate. Various quantities of sea 
water or egg factors were then added to the chamber and the new respiratory rates were calculated over a period of $5 \mathrm{~min}$. Respiratory rates were expressed in terms of $\mathrm{ng}$ atoms $\mathrm{O}$ consumed $/ \mathrm{min} / \mathrm{mg}$ (wet weight) spermatozoa.

Different preparations of spermatozoa displayed considerable variation in the absolute rates of respiration, although consistency in qualitative patterns was always observed. The respiratory data presented therefore represent typical experiments.

Stability of the egg factors at $115^{\circ} \mathrm{C}$. The crude mixture of egg factors collected in sea water (pH 8.0) was examined for stability of activity at neutral $\mathrm{pH}$ (by addition of $1.0 \mathrm{~N}-\mathrm{HCl}$ to the sea water to bring the final $\mathrm{pH}$ to 7.0 ) and at acid $\mathrm{pH}$ (by addition of $11.6 \mathrm{~N}-\mathrm{HCl}$ to give a final concentration of $1 \mathrm{~N}-\mathrm{HCl}, \mathrm{pH} 0.63$ ). Egg factors treated in this manner were then placed in a Griffen-Worden pressure vessel, sealed in vacuo, and incubated at $115^{\circ} \mathrm{C}$. At various times, an aliquot of the mixture was withdrawn and the samples incubated at acid $\mathrm{pH}$ were immediately titrated towards neutral $\mathrm{pH}$ with $11.0 \mathrm{~N}-\mathrm{NaOH}$. The sample was finally neutralized to $\mathrm{pH} 7 \cdot 0$ with Tris buffer. Tris buffer was also added in equal quantities to the samples incubated at neutral $\mathrm{pH}$. The respective samples were then incubated with washed $L$. pictus spermatozoa, and respiration and cyclic nucleotide concentrations were determined as indicated above.

Column chromatography. Sephadex G-50, Bio Gel A 1.5 m, Sephadex G-10 and Bio Gel P-6 resins were suspended, equilibrated, and run in sea water ( $\mathrm{pH} \mathrm{8.0)}$ ) at room temperature $\left(24^{\circ} \mathrm{C}\right)$. All molecular weight calibration standards were suspended in sea water before chromatography.

\section{Results}

All respiratory and cyclic nucleotide studies, unless otherwise noted, were performed by preincubating the spermatozoa with $2.2 \mathrm{~mm}$-theophylline and then incubating these cells with the egg factors. An example of the dramatic alteration of sperm respiration rates caused by the addition of a small amount of the crude mixture of egg factors is shown in Text-fig. 1. The respiratory rates were altered rapidly by, and continued at a linear rate after, addition of the egg factors. The respiratory stimulation by the factors was concentration-dependent (Text-fig. 2c). When

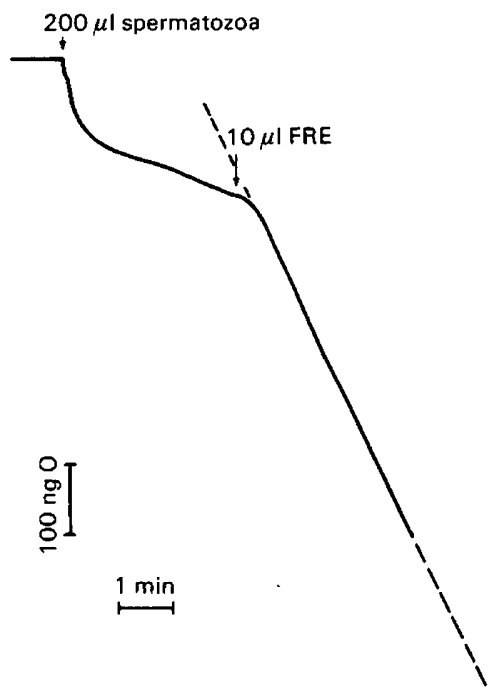

Text-fig. 1. The effect of $S$. purpuratus egg factors (FRE) on the respiratory rate of $L$. pictus spermatozoa at $17^{\circ} \mathrm{C}$. The spermatozoa were preincubated with $2.2 \mathrm{mM}$-theophylline before addition of the egg factors. The figure represents a typical oxygraph tracing. 


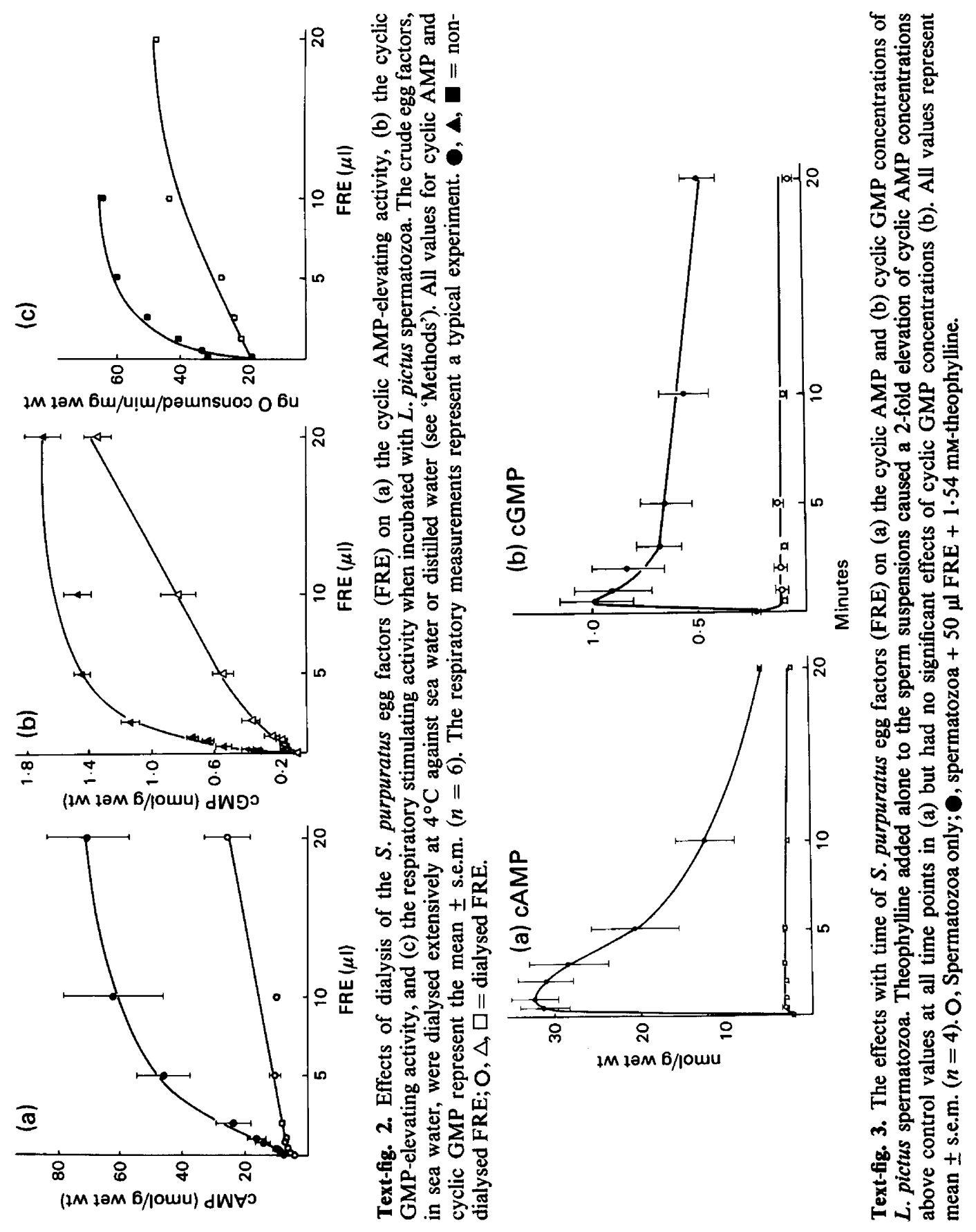


S. purpuratus egg factors were incubated with $L$. pictus spermatozoa, there was a concentrationdependent increase in both cyclic AMP and cyclic GMP concentrations (Text-fig. 2a, b). Egg factors and theophylline separately increased sperm cyclic AMP and cyclic GMP concentrations in a concentration-dependent manner (data not shown), but these changes were not as large as the synergistic responses observed when the egg factors and theophylline were combined (Textfig. 2a, b). The egg factors appeared to be consistently more potent in elevating cyclic GMP concentrations since $1 \mu \mathrm{l}$ and $4 \mu \mathrm{l}$ crude egg factors were required for half-maximal elevations of sperm cyclic GMP and cyclic AMP concentrations, respectively (Text-fig, 2a, b).

The time course of the egg factor-induced changes in sperm cyclic AMP (Text-fig. 3a) and cyclic GMP (Text-fig. 3b) concentrations were also studied. Cyclic AMP and cyclic GMP concentrations were elevated maximally between 0.5 and $2 \mathrm{~min}$, and then the levels declined gradually as a function of time.

Dialysis of the egg factors. As shown in Text-fig. 2, dialysis significantly reduced the cyclic AMP elevating activity (Text-fig. 2a) and the cyclic GMP elevating activity (Text-fig. 2b) of the crude egg factor mixture. A similar reduction in the respiratory stimulating activity was also observed (Text-fig. 2c).

Thermal and acid stability of the egg factors. Heating the egg factors at neutral $\mathrm{pH}$ for up to $8 \mathrm{~h}$ had no significant effects on any of the 3 activities measured (data not shown). However, heating at acid $\mathrm{pH}$ led to a complete loss of these activities within $2 \mathrm{~h}$ after the start of the incubation (Text-fig. 4).

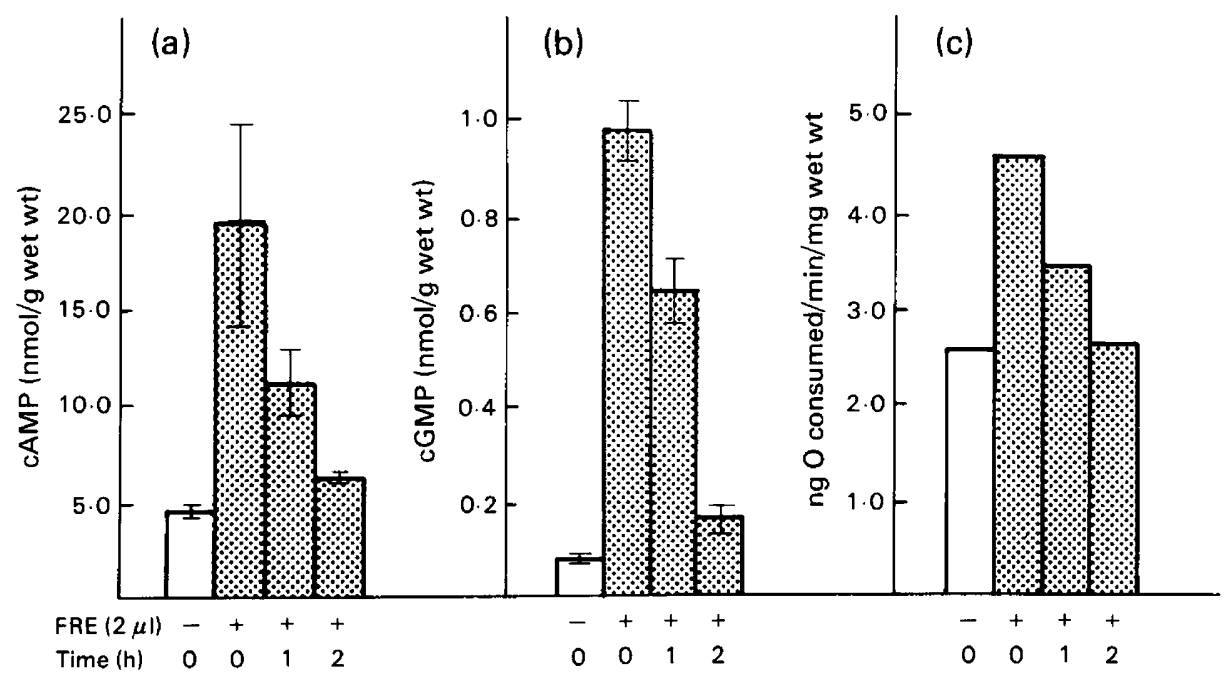

Text-fig. 4. The effects of incubation of the $S$. purpuratus egg factors (FRE) at $115^{\circ} \mathrm{C}$ in $1 \mathrm{~N}-$ $\mathrm{HCl}$ on: (a) cyclic AMP-elevating activity, (b) cyclic GMP-elevating activity and (c) respiration-stimulating activity, when incubated with $L$. pictus spermatozoa. Cyclic nucleotide values represent mean \pm s.e.m. $(n=6)$. Respiratory measurements represent a typical experiment.

Gel filtration of the egg factors. When the crude mixture of egg factors was applied to BioGel A $1.5 \mathrm{~m}$ and Sephadex G-50 columns equilibrated with sea water, respiratory-stimulating activity, cyclic AMP-elevating activity, and cyclic GMP-elevating activity elution profiles were very similar (data not shown). Gel filtration of the egg factors on Sephadex G-10 and Bio-Gel P6 columns, calibrated with dextran blue T-2000, poly-L-lysine, polyethylene glycol 4000, and polyethylene glycol 900 , demonstrated that the three activities migrated coincidentally in a molecular weight range of between 1000 and 2000 (data not shown). 
Partial purification of the low molecular weight egg factor. When 1 litre sea water containing the egg factors was added to 3 litres $95 \%$ ethanol, with constant stirring at $0-2{ }^{\circ} \mathrm{C}$, a large molecular weight egg-associated component was precipitated. The small molecular weight respiratory stimulatory factor was not precipitated by this step and remained in the supernatant fluid. Factor activity throughout this and subsequent purification steps was monitored by measuring sperm respiratory stimulation. The suspension containing both factors was then centrifuged at $3500 \mathrm{~g}$ for $15 \mathrm{~min}$ and the supernatant fluid collected and flash evaporated to a final volume of $800-1000 \mathrm{ml}$. The concentrate was then acidified to $\mathrm{pH} 5.0$ with $\mathrm{HCl}$ and applied to a $2.6 \times 30 \mathrm{~cm}$ charcoal column which had been equilibrated with 51 distilled water.

Under these conditions, all of the factor activity was adsorbed to the column. The column was then washed successively with $5 \mathrm{l} \mathrm{H}_{2} \mathrm{O}, 5 \mathrm{l} 50 \%$ ethanol and then $51 \mathrm{H}_{2} \mathrm{O}$. The factor remained completely adsorbed to the column throughout this washing procedure. Elution of the factor from the column was accomplished by the addition of 31 of a solution containing $70 \%$ ethanol and $0.2 \%\left(\mathrm{NH}_{4}\right) \mathrm{OH}$. The eluate was flash evaporated and the remaining aqueous phase was freeze-dried. This freeze-dried material was then resuspended in $10-15 \mathrm{ml} 70 \%$ ethanol and $5 \mathrm{ml}$ of the solution was applied to a $2.6 \times 80 \mathrm{~cm}$ Sephadex LH-20 column, equilibrated with $70 \%$ ethanol and $0.1 \mathrm{M}-\mathrm{NaCl}$. The fractions from the column containing the factor were then pooled and flash evaporated. The remaining aqueous solution containing the factor was used in the subsequent studies. The recovery of factor throughout these procedures, as determined by the amount of factor required for half-maximal stimulation of respiration, was about $30 \%$.

Effects of pronase on the activity of the low molecular weight egg factor. When the partly purified factor was incubated with $20 \mu \mathrm{g}$ pronase $/ \mathrm{ml}$, respiratory-stimulating activity disappeared within $2 \mathrm{~h}$ (data not shown). Although these results suggest that the factor is a peptide, it is still possible that the factor is adsorbed by pronase at a rate similar to that expected for enzymic degradation. Trypsin and a variety of other hydrolytic enzymes failed to inactivate the factor.

Organic solvent extraction of the low molecular weight factor. An aliquot $(1 \mathrm{ml})$ of a solution containing the factor was mixed with $5 \mathrm{ml}$ chloroform, ether or benzene. The aqueous phase was then tested for activity, and it was observed that the factor remained quantitatively in this phase.

Molecular weight. The respiratory-stimulating factor migrated at the front of Sephadex G-10 columns (exclusion limit approximately 1000), but migrated between cytochrome c (mol. wt 13000 ) and ${ }^{3} \mathrm{H}_{2} \mathrm{O}$ (inclusion volume) on Sephadex G-50 columns. Subsequently, the factor was found to migrate with a molecular weight of $1000-2000$ as estimated on Bio-Gel P-6 columns by using $\left[{ }^{3} \mathrm{H}\right]$ polyethylene glycol (mol. wt 4000 and 900) and poly-L-lysine (mol. wt 3000) as standards.

Exogenous cyclic nucleotides. Incubation of $5 \mathrm{mM}$-cyclic AMP, cyclic GMP, 8-Br-cyclic GMP or of dibutyryl cyclic AMP with sea urchin spermatozoa did not stimulate sperm respiration at $\mathrm{pH} 8.0$ in the presence or absence of theophylline (data not shown).

\section{Discussion}

A number of workers have demonstrated species-specific effects of invertebrate egg factors on sperm respiration, ranging from positive effects (Gray, 1928; Carter, 1930; Hathaway, 1963), to no effects (Tyler, 1948) or negative effects (Rothschild 1952). The chemical nature of the sperm respiratory-stimulating factor remains unclear, and it may be different from species to species (Woodward, 1918; Clowes \& Bachman, 1921; Carter, 1930; Hartmann \& Schartau, 1939; Tyler, 1939; Cornman, 1941; Lybing \& Hagström, 1957; Hathaway, 1960, 1963; Ohtake, $1976 \mathrm{a}, \mathrm{b})$. In general, however, the factor appears to be of low molecular weight and to be heat stable. 
Studies in mammalian systems have provided evidence that factors which can stimulate sperm motility and respiration exist in the male and female reproductive tract fluids (Iritani, Gomes \& VanDemark, 1969; Morton \& Chang, 1973; Lindholmer, 1974; Hoskins et al., 1975; Acott \& Hoskins, 1976; Bavister \& Yanagimachi, 1977; Brandt, Acott, Johnson \& Hoskins, 1977), certain organ extracts (Bavister, Yanagimachi \& Teichman, 1976), and in the sera of a variety of animals (Morton \& Bavister, 1974; Bavister, 1975). The factor studied by Bavister (1975) and Bavister et al. (1976) is known to be of low molecular weight. Although the biochemical basis for the stimulatory properties of these mammalian factors has not been thoroughly investigated, it is known that mammalian sperm motility, respiration rates, and fructolytic rates can be maintained or increased by cyclic nucleotide phosphodiesterase inhibitors and by exogenous cyclic AMP or cyclic GMP (Garbers, First, Sullivan \& Lardy, 1971a; Garbers et al., 1971b, 1973a, b; Hoskins, 1973; Frenkel et al., 1973; Schoenfeld, Amelar \& Dubin, 1975). In addition, positive correlations between endogenous sperm cyclic AMP levels and sperm motility and respiration rates have been demonstrated (Tash \& Mann, 1973; Morton et al., 1974; Hoskins, Stephens \& Hall, 1974; Cascieri et al., 1976; Gray, Drummond, Luk, Hardman \& Sutherland, 1976; Kopf \& Garbers, 1978). It is, therefore, possible that the cyclic nucleotides serve as intracellular mediators for some or all of the sperm functional changes that occur in response to these mammalian factors. The observations of Berger \& Clegg (1977) on the activation of pig sperm adenylate cyclase by sow uterine fluids support this suggestion.

The present report demonstrates that there is a low molecular weight factor released from the eggs of $S$. purpuratus sea urchins that will elevate the respiratory rates and the cyclic AMP and cyclic GMP concentrations of $L$. pictus spermatozoa. This report is the first to demonstrate an egg factor-induced elevation of sperm cyclic GMP concentrations. However, a purified large molecular weight factor that causes large elevations of sperm cyclic AMP concentrations failed to elevate sperm respiration rates in the homologous species (G. S. Kopf \& D. L. Garbers, unpublished data), and elevation of sperm cyclic AMP concentrations only may not result in increased respiration rates. Whether or not cyclic GMP may mediate some of these respiratory changes remains to be studied, although exogenously added cyclic nucleotides did not appear to mimic the respiratory stimulation of the egg factors in L. pictus spermatozoa in the presence or absence of theophylline. Such studies are difficult to interpret, however, due to possible permeability problems.

We thank Ms Helen Watkins, Ms D. Janette Tubb, and Ms Marvist Ann Parks for their excellent technical assistance. This work was supported by NIH grant HD-10254.

\section{References}

Acott. T.S. \& Hoskins, D.D. (1976) Characterization of factors which initiate forward motility in sperm from the bovine caput epididymis. Fedn Proc. Fedn Am. Socs exp. Biol. 35, 1617, Abstr.

Bavister, B.D. (1975) Properties of the sperm motilitystimulating component derived from human serum. $J$. Reprod. Fert. 43, 363-366.

Bavister, B.D. \& Yanagimachi, R. (1977) The effects of sperm extracts and energy sources on the motility and acrosome reaction of hamster spermatozoa in vitro. Biol. Reprod. 16, 228-237.

Bavister, B.D., Yanagimachi, R. \& Teichman, R.J. (1976) Capacitation of hamster spermatozoa with adrenal gland extracts. Biol. Reprod. 14, 219221 .
Berger, T. \& Clegg, E.D. (1977) Effect of female reproductive tract secretions on adenyl cyclase and phosphodiesterase of porcine sperm. Proc. 3rd Int. Conf. Cyclic Nucleotides, New Orleans, Abstr. WA-152.

Brandt, H., Acott, T.S., Johnson, D.J. \& Hoskins, D.D. (1977) The initiation of forward motility in bovine caput spermatozoa by rete testicular and epididymal fluid protein(s). Proc. 10th Ann. Meeting, Soc. Study Reprod., Austin, Abstr. 30.

Brostrom, C.O. \& Kon, C. (1974) An improved protein binding assay for cyclic AMP. Analyt. Biochem. 58, $459-468$.

Carter, G.S. (1930) Thyroxine and the oxygen consumption of the spermatozoa of Echinus miliaris. $J$. exp. Biol. 7, 41-48. 
Cascieri, M., Amann, R.P. \& Hammerstedt, R.H. (1976) Adenine nucleotide changes at initiation of bull sperm motility. J. biol. Chem. 251, 787-793.

Clowes, G.H.A. \& Bachman, E. (1921) A volatile, sperm-stimulating substance derived from marine eggs. J. biol. Chem., 26, 31-32, Abstr.

Cornman, I. (1941) Sperm activation by Arbacia egg extracts, with special reference to echinochrome. Biol. Bull. mar. Biol. Lab., Woods Hole 80, 202207.

Dan, J.C. (1952) Studies on the acrosome. I. Reaction to egg-water and other stimuli. Biol. Bull. mar. Biol. Lab., Woods Hole 103, 54-66.

Frenkel, G., Peterson, R.N. \& Freund, M. (1973) The role of adenine nucleotides and the effect of caffeine and dibutyryl cyclic AMP on the metabolism of guinea pig epididymal spermatozoa. Proc. Soc. exp. Biol. Med. 144, 420-425.

Garbers, D.L. \& Hardman, J.G. (1975) Factors released from sea urchin eggs affect cyclic nucleotide metabolism in sperm. Nature, Lond. 257, 677-678.

Garbers, D.L. \& Hardman, J.G. (1976) Effects of egg factors on cyclic nucleotide metabolism in sea urchin sperm. J. Cyclic Nucleotide Res. 2, 59-70.

Garbers, D.L., First, N.L., Sullivan, J.J. \& Lardy, H.A. (1971a) Stimulation and maintenance of ejaculated bovine spermatozoan respiration and motility by caffeine. Biol. Reprod. 5, 336-339.

Garbers, D.L., Lust, W.D., First, N.L. \& Lardy, H.A. (1971b) Effects of phosphodiesterase inhibitors and cyclic nucleotides on sperm respiration and motility. Biochemistry, N.Y. 10, 1825-1831.

Garbers, D.L., First, N.L. \& Lardy, H.A. (1973a) The stimulation of bovine epididymal sperm metabolism by cyclic nucleotide phosphodiesterase inhibitors. Biol. Reprod. 8, 589-598.

Garbers, D.L., First, N.L., Gorman, S.K. \& Lardy, H.A. (1973b) The effects of cyclic nucleotide phosphodiesterase inhibitors on ejaculated porcine spermatozoan metabolism. Biol. Reprod. 8, 599-606.

Gilman, A.G. (1970) A protein binding assay for adenosine $3^{\prime}, 5^{\prime}$-cyclic monophosphate. Proc. natn. Acad. Sci. U.S.A. 67, 305-312.

Gray, J. (1928) The effect of egg secretions on the activity of spermatozoa. J. exp. Biol. 5, 362-365.

Gray, J.P., Drummond, G.I., Luk, D.W.T., Hardman, J.G. \& Sutherland, E.W. (1976) Enzymes of cyclic nucleotide metabolism in invertebrate and vertebrate sperm. Archs Biochem. Biophys. 172, 20-30.

Harper, J.F. \& Brooker, G. (1975) Femtomole sensitive radioimmunoassay for cyclic AMP and cyclic GMP after $2^{\prime} 0$-acetylation by acetic anhydride in aqueous solution J. Cyclic Nucleotide Res. 1, 207-218.

Hartmann, M. \& Schartau, O. (1939) Untersuchungen über die Befruchtungs-stoffe der Seeigel. Biol. Zentralbl. 59, 571-587.

Hathaway, R.R. (1960) Stimulation of Arbacia sperm respiration by egg substances Biol. Bull. mar. Biol. Lab., Woods Hole 119, 318-319.

Hathaway, R.R. (1963) Activation of respiration in sea urchin spermatozoa by egg water. Biol. Bull. mar. Biol. Lab., Woods Hole 125, 486-498.

Hoskins, D.D. (1973) Adenine nucleotide mediation of fructolysis and motility in bovine epididymal spermatozoa. J. biol. Chem. 248, 1135-1140.
Hoskins, D.D., Stephens, D.T. \& Hall, M.L. (1974) Cyclic adenosine $3^{\prime}, 5^{\prime}$-monophosphate and protein kinase levels in developing bovine spermatozoa. $J$. Reprod. Fert. 37, 131-133.

Hoskins, D.D., Hall, M.L. \& Munsterman, D. (1975) Induction of motility in immature bovine spermatozoa by cyclic AMP phosphodiesterase inhibitors and seminal plasma Biol. Reprod. 13, 168176.

Iritani, A., Gomes, W.R. \& VanDemark, N.L. (1969) The effect of whole, dialyzed and heated female genital tract fluids on respiration of rabbit and ram spermatozoa. Biol. Reprod. 1, 77-82.

Kopf, G.S. \& Garbers, D.L. (1978) Correlation between sea urchin sperm respiratory rates and cyclic AMP concentrations as a function of cell dilution. Biol. Reprod. 17, 229-233.

Lillie, F.R. (1913) Studies on fertilization. V. The behavior of the spermatozoa of Nereis and Arbacia with special reference to egg extractives. J. exp. Zool. 14, 515-574.

Lindholmer, C.H. (1974) The importance of seminal plasma for human sperm motility. Biol. Reprod. 10, $533-542$.

Lybing, S. \&. Hagström, B.E. (1957) Isolation of a fertilization-promoting factor from egg water of Psammechinus miliaris. Expl Cell Res. 13, 60-68.

Morton, B. \& Chang, T.S.K. (1973) The effect of fluid from the cauda epididymis, serum components and caffeine upon the survival of diluted epididymal hamster spermatozoa. J. Reprod. Fert. 35, 255-263.

Morton, B., Harrigan-Lum, J., Albagli, L. \& Jooss, T. (1974) The activation of motility in quiescent hamster sperm from the epididymis by calcium and cyclic nucleotides. Biochem Biophys. Res. Commun. 56, 372-379.

Morton, D.B. \& Bavister, B.D. (1974) Fractionation of hamster sperm-capacitating components from human serum by gel filtration. J. Reprod. Fert. 40, 491-493.

Ohtake, H. (1976a) Respiratory behavior of sea-urchin spermatozoa: effect of $\mathrm{pH}$ and egg water on the respiratory rate. Expl Zool. 198, 303-312.

Ohtake, H. (1976b) Respiratory behavior of sea-urchin spermatozoa: Sperm activating substance obtained from jelly coat of sea-urchin eggs. Expl Zool. 198, 313-322.

Rosado, A., Hicks, J.J., Reyes, A. \& Blanco, I. (1974) Capacitation in vitro of rabbit spermatozoa with cyclic adenosine monophosphate and human follicular fluid. Fert. Steril. 25, 821-824.

Rothschild, Lord (1952) The behavior of spermatozoa in the neighborhood of eggs. Int. Rev. Cytol. 1, 257263.

Schoenfeld, C., Amelar, R.D. \& Dubin, L. (1975) Stimulation of ejaculated human spermatozoa by caffeine. Fert. Steril. 26, 158-161.

Schultz, G., Böhme, E. \& Hardman, J.G. (1974) Separation and purification of cyclic nucleotides by ion-exchange resin column chromatography. Methods Enzymol. 38, 9-20.

Steiner, A.L., Kipnis, D.M., Utiger, R. \& Parker, C. (1969) Radioimmunoassay for the measurement of adenosine 3',5'-cyclic phosphate. Proc. natn. Acad. Sci., U.S.A. 64, 367-373. 
Tash, J.S. \& Mann, T. (1973) Adenosine 3',5'-cyclic monophosphate in relation to motility and senescence of spermatozoa. Proc. R. Soc. B 184, 109-114.

Tubb, D.J., Kopf, G.S. \& Garbers, D.L. (1979) Starfish and horseshoe crab egg factors cause elevations of cyclic nucleotide concentrations in spermatozoa from starfish and horseshoe crabs. J. Reprod. Fert. 56, 539-542.

Tyler, A. (1939) Crystalline echinochrome and spino- chrome: their failure to stimulate the respiration of eggs and sperm of Strongylocentrotus. Proc. natn. Acad. Sci. U.S.A. 24, 523-528.

Tyler, A. (1948) Fertilization and immunity. Physiol. Rev. 28, 180-219.

Woodward, A.E. (1918) Studies on the physiological significance of certain precipitates from the eggsecretions of Arbacia and Asterias. J. exp. Zool. 26, 459-501.

Received 30 January 1979 